\title{
Pharmacologic Approaches for Adapting Proteostasis in the Secretory Pathway to Ameliorate Protein Conformational Diseases
}

\author{
Jeffery W. Kelly \\ Departments of Chemistry and Molecular Medicine; and The Skaggs Institute for Chemical Biology, The Scripps \\ Research Institute, La Jolla, California 92037 \\ Correspondence: jkelly@scripps.edu
}

\begin{abstract}
Maintenance of the proteome, ensuring the proper locations, proper conformations, appropriate concentrations, etc., is essential to preserve the health of an organism in the face of environmental insults, infectious diseases, and the challenges associated with aging. Maintaining the proteome is even more difficult in the background of inherited mutations that render a given protein and others handled by the same proteostasis machinery misfolding prone and/or aggregation prone. Maintenance of the proteome or maintaining proteostasis requires the orchestration of protein synthesis, folding, trafficking, and degradation by way of highly conserved, interacting, and competitive proteostasis pathways. Each subcellular compartment has a unique proteostasis network compromising common and specialized proteostasis maintenance pathways. Stress-responsive signaling pathways detect the misfolding and/or aggregation of proteins in specific subcellular compartments using stress sensors and respond by generating an active transcription factor. Subsequent transcriptional programs up-regulate proteostasis network capacity (i.e., ability to fold and degrade proteins in that compartment). Stress-responsive signaling pathways can also be linked by way of signaling cascades to nontranscriptional means to reestablish proteostasis (e.g., by translational attenuation). Proteostasis is also strongly influenced by the inherent kinetics and thermodynamics of the folding, misfolding, and aggregation of individual proteins, and these sequence-based attributes in combination with proteostasis network capacity together influence proteostasis. In this review, we will focus on the growing body of evidence that proteostasis deficits leading to human pathology can be reversed by pharmacologic adaptation of proteostasis network capacity through stress-responsive signaling pathway activation. The power of this approach will be exemplified by focusing on the ATF6 arm of the unfolded protein response stress responsive-signaling pathway that regulates proteostasis network capacity of the secretory pathway.
\end{abstract}

-ukaryotic protein homeostasis, or proteostaEsis, is maintained by a diverse number of integrated pathways that sometimes complement each other and in other scenarios compete to regulate the function of the proteome (Morimoto 1998; Balch et al. 2008; Morimoto and Cuervo 2009; Powers et al. 2009; Jarosz et al. 2010; Taipale et al. 2010; Hartl et al. 2011). Com-

Editors: Richard I. Morimoto, F. Ulrich Hartl, and Jeffery W. Kelly

Additional Perspectives on Protein Homeostasis available at www.cshperspectives.org

Copyright (C) 2020 Cold Spring Harbor Laboratory Press; all rights reserved; doi: 10.1101/cshperspect.a034108

Cite this article as Cold Spring Harb Perspect Biol 2020;12:a034108 
J.W. Kelly

partment-specific stress-responsive signaling pathways regulate the capacity of the proteostasis network in that compartment, utilizing sensors that detect higher than normal levels of protein misfolding and/or aggregation (Didomenico et al. 1982; Morimoto 1998; Mori 2000; Schröder and Kaufman 2005; Marciniak and Ron 2006; Ron and Walter 2007; Westerheide et al. 2009; Walter and Ron 2011). Activation of a stress-responsive signaling pathway associated with a particular cellular compartment results in generation or activation of a transcription factor that orchestrates a transcriptional program to enhance the proteostasis capacity of that compartment. Folding capacity almost always increases in concert with degradation capacity, highlighting the delicate balance between protein production, folding, and degradation (Balch et al. 2008; Morimoto and Cuervo 2009; Lee et al. 2010). Another key feature of the restoration of proteostasis associated with stressresponsive signaling is reduced transcription of normal cellular messenger RNAs (mRNAs), reduced splicing of normal transcripts, and reduced translation of preexisting mRNAs (Yost et al. 1990; Shang et al. 2007; Ghosh et al. 2010). Importantly, these mechanisms sharply decrease the proteome load on the proteostasis network, maximizing the possibility that proteostasis will be reestablished (Yost et al. 1990; Ron and Walter 2007; Shang et al. 2007; Ghosh et al. 2010; Walter and Ron 2011). When proteostasis is restored through these highly orchestrated responses, stress-responsive signaling subsides owing to the production of negative regulators such as chaperones that bind to the stress sensor.

Ribosome-associated chaperones (Maier et al. 2005; Merz et al. 2008; Preissler and Deuerling 2012; Chartron et al. 2016) hand off proteins to multiple folding pathways, including the HSP70-Hsp40-nucleotide exchange factor folding pathway, the Hsp90-cochaperone-folding pathway, or the TRiC chaperonin-folding pathway in the cytosol (Ellis and Hartl 1999; Young et al. 2004; Tang et al. 2007; Yam et al. 2008; Voisine et al. 2010). How these proteostasis network pathways work together and create emergent capacity as a system is only poorly understood. The ubiquitin proteasome system is intimately linked to each of these chaperone systems by kinetic partitioning; futile attempts at folding eventually redirect terminally misfolded substrates to ubiquitin conjugation-mediating degradation (Leggett et al. 2002; Lecker et al. 2006; Finley 2009). Proteasome degradation rids the cell of dangerous aggregation-prone species and reduces the load on the proteostasis network. Similar partitioning, sometimes utilizing ubiquitin conjugation, links unsuccessful folding by chaperone pathways to the lysosomal degradation of these nonnative conformations via autophagy (Cuervo and Dice 1996; Kruse et al. 2006; Tsvetkov et al. 2010; Wong and Cuervo 2010; Arias and Cuervo 2011). There appear to be compensatory mechanisms that up-regulate the proteasome when autophagy is impaired and vice versa (Lamark and Johansen 2010; Zhu et al. 2010; Chen and Yin 2011).

While we are far from a systems-level understanding of the functions and regulation of the proteostasis network (Vidal et al. 2011), we do know enough about stress-responsive signaling pathways to begin to manipulate them to downand up-regulate proteostasis network components in the appropriate stoichiometry to reestablish proteostasis (Mori 2000; Boyce et al. 2005; Schröder and Kaufman 2005; Shang et al. 2007; Walter and Ron 2011; Calamini et al. 2012; Gallagher and Walter 2016; Gallagher et al. 2016). This evolved regulatory strategy appears to be able to alleviate the deficiencies of proteostasis that lead to specific diseases when we are young (Westerheide et al. 2004, 2009; Westerheide and Morimoto 2005; Dai et al. 2007; Balch et al. 2008; Mu et al. 2008a,b; Cowen et al. 2009; Powers et al. 2009; Whitesell and Lindquist 2009; Tsaytler et al. 2011). In model organisms, stressresponsive signaling pathways are attenuated upon aging via epigenetic and likely other mechanisms (Morley et al. 2002; Cohen et al. 2006, 2009, 2010; Ben-Zvi et al. 2009; Labbadia and Morimoto 2015; Solis et al. 2018). The ultimate goal is to be able to activate stress-responsive signaling pathways in the elderly exhibiting degenerative diseases, including neurodegenerative diseases.

Notably, the misfolding and/or aggregation of individual vulnerable proteins not only com- 
promise their own folding, but that of additional proteins sharing common proteostasis pathways (Powers et al. 2009). Even one mutated aggregation-prone protein can consume considerable proteostasis network capacity, putting numerous members of the proteome that require this capacity at risk of misfolding and aggregation (Gidalevitz et al. 2006). In turn, this leads to wider proteome misfolding or aggregation if stress-responsive signaling cannot efficiently reestablish proteostasis (Balch et al. 2008). Thus, small-molecule, stress-responsive signaling pathway activators are one way to counter the influence of a misfolding- or aggregation-prone protein in an organism and holds high promise for increasing health span, the number of years free of significant pathology (Westerheide et al. 2004, 2009; Mu et al. 2008b).

In contrast to adapting proteostasis network activity (i.e., the biology of protein homeostasis), another approach is to make the energetics of a specific misfolding-prone protein less problematic, utilizing small-molecule-binding-associated stabilization (Miroy et al. 1996; Sawkar et al. 2002, 2006; Cohen and Kelly 2003; Hammarstrom et al. 2003; Razavi et al. 2003; Johnson et al. 2005; Tojo et al. 2006; Yu et al. 2007; Choi et al. 2010; Johnson et al. 2010; Bulawa et al. 2012; Makley et al. 2015). While the sequence of a protein specifies its folding, unfolding, misfolding energetics, as well as its concentration-dependent aggregation kinetics, the energetics of an individual mutant protein prone to misfolding can be selectively tuned if the folded state of that protein has a hydrophobic depression or cavity where a small molecule can bind (Miroy et al. 1996; Sawkar et al. 2002, 2006; Cohen and Kelly 2003; Hammarstrom et al. 2003; Razavi et al. 2003; Johnson et al. 2005; Tojo et al. 2006; Yu et al. 2007; Choi et al. 2010; Bulawa et al. 2012; Makley et al. 2015). Small molecules that bind to the native state of mutant proteins lower their folding free energy and thus increase the folded population relative to the unfolded, misfolded, and aggregated states. After folding is complete, pharmacologic chaperone binding to the native state can slow unfolding events that can lead to proteolysis and/or aggregation, hence the reason some of these pharmacologic chaperones are called kinetic stabilizers (Johnson et al. 2005; Sekijima et al. 2006; Tojo et al. 2006; Bulawa et al. 2012). Indeed, targeting a particular misfolding-prone protein with a small molecule that binds to its native state not only can restore proteostasis of that energetically compromised protein, but this strategy also has the promise of restoring proteostasis to other energetically compromised proteins that require the same proteostasis network components for folding (Gidalevitz et al. 2006). Now that there are quite a few pharmacologic chaperones/kinetic stabilizers available to stabilize individual proteins, some of which are regulatory agency approved, it is important to try these at restoring proteostasis in diseases of interest where the misfolding-prone protein itself lacks available kinetic stabilizers (Miroy et al. 1996; Fan et al. 1999; Fan 2001, 2003; Sawkar et al. 2002; Hammarstrom et al. 2003; Razavi et al. 2003; Sekijima et al. 2006; Tojo et al. 2006; Bulawa et al. 2012). For example, if a given secreted misfolding-prone protein linked to a disease for which there is no disease-modifying drug therapy utilizes the endoplasmic reticulum (ER) Hsp70-40nucleotide exchange factor pathway for folding, it is possible that transthyretin and $\alpha 1$ antitrypsin pharmacologic chaperones/kinetic stabilizers could ameliorate a misfolding disease caused by a protein that they do not target. The hypothesis is that by making wild-type transthyretin or $\alpha 1$ antitrypsin folding more efficient pharmacologically, this would take a load off the ER Hsp70-40-nucleotide exchange factor pathway. This strategy might afford the Hsp7040-nucleotide exchange factor pathway sufficient capacity to restore proteostasis to a disease-associated protein that also utilizes the same proteostasis pathway.

In this review, we focus on pharmacological adaptation of the ATF6 arm of the unfolded protein response stress-responsive signaling pathway for rebalancing proteostasis in the ER and downstream secretory pathway (Yoshida et al. 1998; Nadanaka et al. 2006, 2007; Wiseman et al. 2010; Plate et al. 2016a; Paxman et al. 2018). This approach is appealing because enhancement of the biology of proteostasis might 
J.W. Kelly

be capable of ameliorating complex multifaceted problems and holds particular promise in combating aging-associated degenerative maladies linked to secreted proteins (Shoulders et al. 2013; Cooley et al. 2014). However, proteostasis networks are finely tuned and highly integrated, hence manipulating them does raise the specter of unintended consequences, especially if alterations are carried out directly (e.g., by targeting Hsp90) as opposed to activating a given stress-responsive signaling pathway that transcriptionally controls Hsp90. Hence, we focus on altering proteostasis network capacity through stress-responsive signaling pathways, namely, the ATF6 pathway. That said, I see a future where pharmacologic chaperones/kinetic stabilizers will be used in combination with stress-responsive signaling pathway modulators ( $\mathrm{Mu}$ et al. 2008b). Stress-responsive signaling pathway activators resculpt the folding free energy diagram up to, but not including, the native state, lowering aggregation and in some cases catalyzing folding (i.e., pushing the protein toward the native state) (Fig. 1). In contrast, a pharmacologic chaperone binds to the native state of a protein, lowering its free energy and increasing the population of the folded state by pulling the polypeptide from less well-folded states (Fig. 1; Schröder and Kaufman 2005; Ron and Walter 2007; Mu et al. 2008b; Wiseman et al. 2010; Walter and Ron 2011).

\section{THE PROTEOSTASIS CHALLENGES OF THE ENDOPLASMIC RETICULUM SECRETORY COMPARTMENT}

Approximately one-third of the proteome traffics through the ER to the Golgi and onto the lysosome and the extracellular space, by way of highly dynamic networks of membrane-delimited vesicles traveling along microtubules (Fewell et al. 2001; Schröder and Kaufman 2005; Ron and Walter 2007). The vesicles bud from one secretory pathway subcompartment and fuse with the next in a highly regulated manner. The secreted proteome faces a number of challenges, including extreme crowding, the requirement to make stabilizing disulfide bonds by ox- idation, the high kinetic energy of protein collisions that can facilitate aggregation and lead to gain-of-toxic-function diseases (e.g., liver cancer linked to misfolded and misassembled $\alpha 1$ antitrypsin accumulating in the hepatocyte ER), and the low folded free energy state of the secreted proteome (Eriksson et al. 1986). Consequently, secreted proteins in the ER are susceptible to misfolding and degradation, potentially leading to loss-of-function diseases such as the lysosomal storage diseases wherein an energetically compromised mutant protein is largely degraded by the proteasome or the lysosome (Cohen and Kelly 2003; Mu et al. 2008b). Numerous secreted proteins are cotranslationally modified by branched glycans attached to the side chain of Asn. This so-called N-glycosylation process is key to both folding efficiency and function for both intrinsic reasons (the conserved $\mathrm{N}$-glycan makes native state stabilizing interactions with the protein) (Culyba et al. 2011) and extrinsic reasons ( $N$-glycosylated glycoproteins use the glycan and protein-binding chaperones calnexin and calreticulin pathways for folding and degradation, pathways that are only found in the ER) (Yoshida 2003; Williams 2006; Hebert et al. 2014).

The proteostasis pathways of the ER include the Hsp70-Hsp40-nucleotide exchange factor and Hsp90-cochaperone pathways, which play important roles in folding and degradation of the secreted proteome (Hartl et al. 2011). However, the proteostasis pathways unique to the ER are equally critical: the $N$-glycan- or lectin-binding calnexin- and calreticulin-based proteostasis pathways that help $N$-linked glycoproteins to fold or direct them to degradation through the glucosidases that target chronically misfolded proteins to ER-associated degradation (ERAD) (Ellgaard et al. 1999; Williams 2006; Hebert et al. 2014). There are also numerous protein-processing proteases and protein-folding enzymes in the secretory pathway, including disulfide oxidases and disulfide isomerases, to name a few (Schröder and Kaufman 2005; Ron and Walter 2007; Hartl et al. 2011).

All proteins residing in and passing through the secretory pathway are encoded by nuclear genes. These proteins are cotranslationally in- 


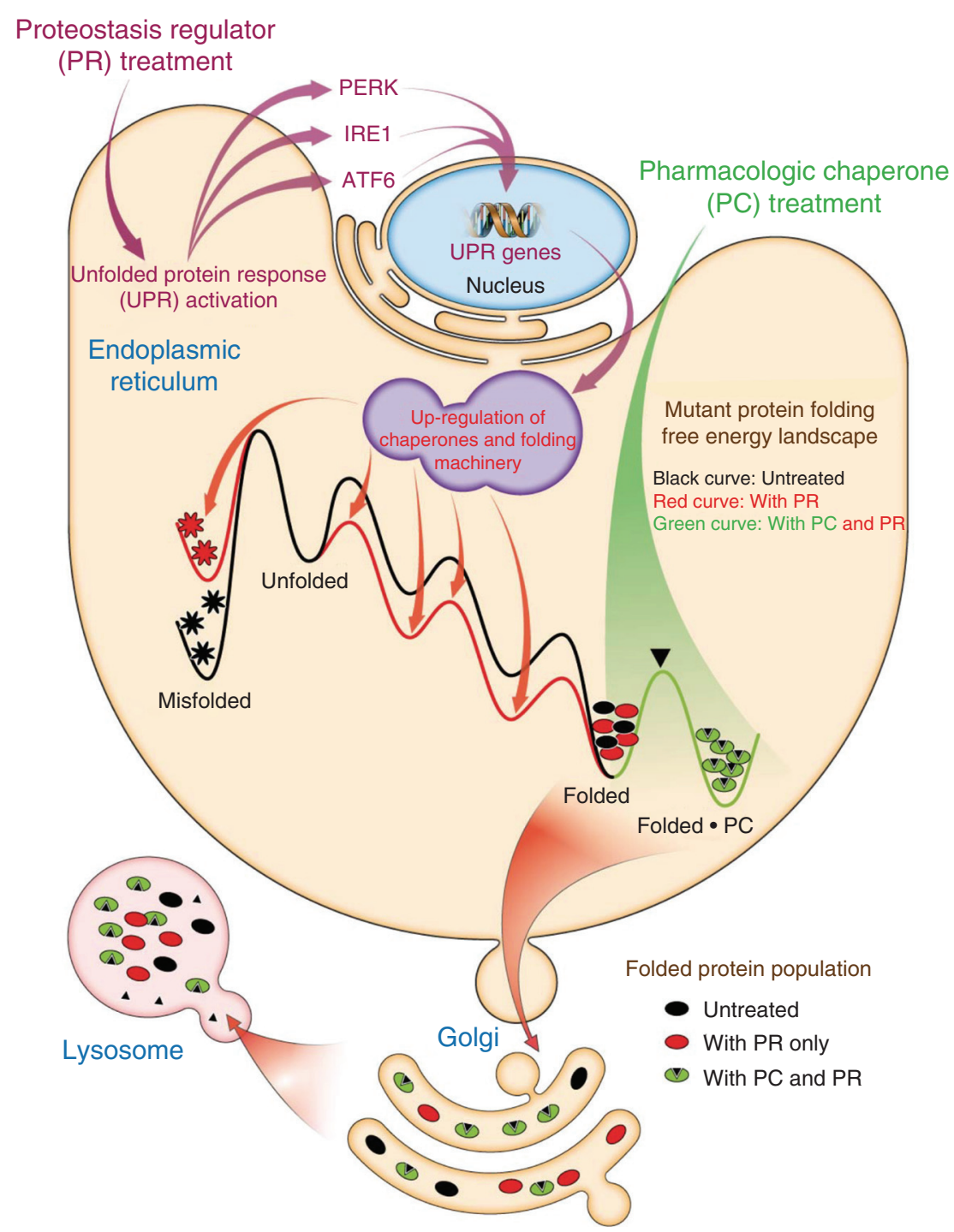

Figure 1. Pharmacologic stress-responsive signaling pathway activation coordinates transcription and translation of chaperone pathways and folding enzymes that resculpt the folding free energy diagram of the mutant proteinof-interest in the endoplasmic reticulum (ER), enhancing its folding and minimizing misfolding, increasing the population of the mutant protein in the folded state. Pharmacologic chaperones bind to the folded state of the mutant protein, lowering its free energy, further increasing its population. Collectively, these mechanisms of action create more folded mutant protein that can engage the trafficking machinery, leading to increased function. (Figure from Mu et al. 2008b; reprinted, with permission, from Elsevier ( 2008 .)

serted into the ER through the translocon, a complicated machine that enables membrane proteins to be inserted into the membrane with the proper topology and fold while simultaneously allowing soluble ER proteins to pass through the translocon in a largely unfolded conformation that is read out by the oligosaccharyl transferase enzyme complex that sometimes attaches an $\mathrm{N}$-glycan when it detects an Asn-xxx-Ser/Thr "sequon" (Shan and Walter 2005; Johnson 2009; Larkin and Imperiali 2011). There is no mechanism for degrading 
J.W. Kelly

nonnative proteins within the confines of the ER that we know of (Nakatsukasa and Brodsky 2008). Instead, these conformationally abnormal proteins are delivered by vesicle trafficking to the lysosome by one of several possible mechanisms (Kruse et al. 2006; Kon and Cuervo 2010) or they are exported into the cytoplasm for degradation by the proteasome, in the process called ERAD (Werner et al. 1996; Brodsky and McCracken 1997; McCracken et al. 1998; McCracken and Brodsky 2003; Brodsky 2012). Both pathways are complex, highly regulated, and incompletely understood.

\section{STRESS-RESPONSIVE SIGNALING PATHWAYS TO MAINTAIN PROTEOSTASIS IN THE ENDOPLASMIC RETICULUM, DOWNSTREAM ORGANELLES, AND IN THE EXTRACELLULAR SPACE}

Historically, it was mysterious how proteostasis problems within the membrane-delimited ER could be perceived, and responded to, by regulatory mechanisms involving transcription in the nucleus and translation in the cytoplasm. The solution is now well understood: there are three key stress-responsive signaling pathways associated with the stress sensors IRE1, ATF6, and PERK (Fig. 2), which have one domain in the ER to sense excessive proteome misfolding and/or aggregation and another in the cytoplasm to enable the transcriptional and translational responses (Mori 2000; Schröder and Kaufman 2005; Ron and Walter 2007; Walter and Ron 2011). As nonnative proteins accumulate within the ER lumen, they recruit away chaperones that negatively regulate each of the three stress sensors. Alternatively, aggregates may directly interact with the stress sensors to activate them. Activation is associated with changes in the conformation and/or quaternary structure of the stress sensor that transduces a signal across the ER membrane to each of the stress sensor's cytoplasmic effector domains (Fig. 2; Mori 2000; Schröder and Kaufman 2005; Ron and Walter 2007; Li et al. 2010; Walter and Ron 2011). This ultimately results in the generation or activation of a transcription factor, leading to an increase or reduction of hundreds of proteostasis network components that create emergent functions, restoring proteostasis. Chaperone levels rise as a result of the

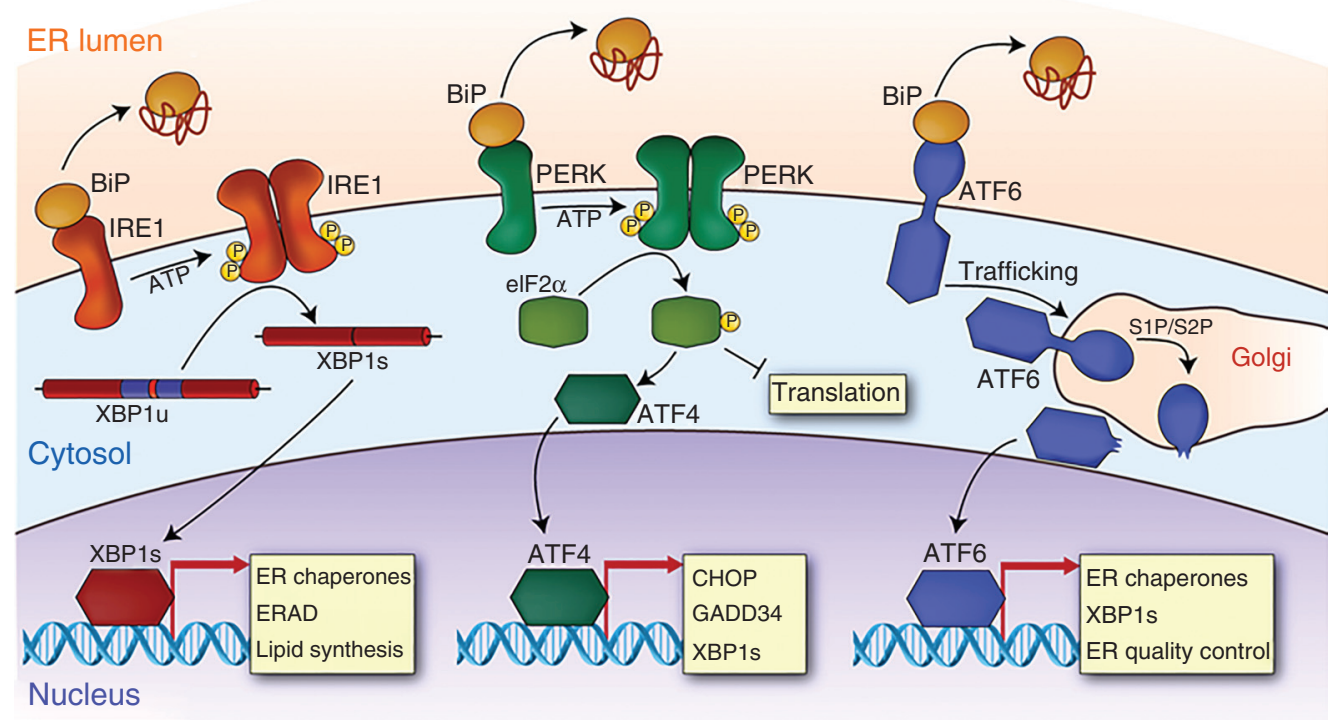

Figure 2. Simplified depiction of the three arms of the unfolded stress response stress-responsive signaling pathway courtesy of Lars Plate. ER, Endoplasmic reticulum; ERAD, ER-associated degradation. (Figure from Wiseman et al. 2010; adapted, with permission, from Elsevier (C) 2010.) 
transcriptional program, and they bind to the stress sensors turning them off.

\section{DISCOVERING AND VALIDATING SMALL- MOLECULE ACTIVATORS OF THE ATF6 ARM OF THE UNFOLDED PROTEIN RESPONSE}

Historically, activation of all three arms of the unfolded protein response (UPR) has been achieved by thapsigargin treatment (inhibitor of the $\mathrm{Ca}^{2+}$ ATPase SERCA that transfers $\mathrm{Ca}^{2+}$ from the cytosol to the ER) or tunicamycin administration (inhibitor of $N$-linked glycosylation) (Mori 2000; Schröder and Kaufman 2005; Ron and Walter 2007; Li et al. 2010; Walter and Ron 2011). Either treatment leads to misfolding and aggregation of the secreted proteome in the ER, which activates stress-responsive signaling by causing proteotoxic stress. While these pharmacologic agents have served investigators well in terms of delineating the signaling pathways for each arm of the UPR, clearly pharmacologically enhancing protein misfolding and aggregation is undesirable for treating proteinopathies.

The small-molecule BIX achieves expression of the ATF6-target gene BiP through an ATF6-dependent mechanism. However, this pharmacologic agent does not induce other genes associated with the ATF6 transcriptional program (Kudo et al. 2008), making it unlikely that BIX will be useful for ameliorating proteinopathies. Regulation of all target genes in the transcriptional response is likely required to get maximal benefit from stress-responsive signaling.

Thus, the effort of the Wiseman and Kelly Laboratories to use a transcriptional profiling approach early in the drug discovery process, before functional assessment, ensured that the small molecules we were pursuing preferentially activated the ATF6 transcriptional program, as opposed to global UPR activation or activation of other stress-responsive signaling pathways (Shoulders et al. 2013). The activation of ATF6 involves trafficking of the full-length ATF6 protein from the ER to the Golgi, where ATF6 is processed by site- 1 and site- 2 proteases (Ye et al. $2000 \mathrm{a}, \mathrm{b})$. This processing releases the active cy- tosolic bZIP transcription factor, enabling its nuclear localization at which location the transcription factor can bind so-called ERSE sites in DNA as a dimer, leading to transcriptional reprogramming (Fig. 2; Yoshida et al. 1998; Nadanaka et al. 2006, 2007).

We employed a cell-based reporter highthroughput screen, together with counterscreens to eliminate compounds that activated undesirable stress-responsive signaling pathways, followed by transcriptional profiling to identify nontoxic small molecules that preferentially activated the ATF6 transcriptional program (Calamini et al. 2012; Plate et al. 2016a). The goal was to identify ATF6 activators that transcriptionally phenocopy the ability of the ATF6 transcription factor generated at a physiological concentration by chemical genetic means to preferentially activate the ATF6 transcriptional program (Shoulders et al. 2013). The screen employed a three-tiered strategy to identify small molecules that preferentially activated the ATF6 arm of the UPR (Plate et al. 2016a). A cell-based transcriptional reporter assay, wherein a fragment of the $\mathrm{BiP}$ (ER Hsp70) promoter driving expression of firefly luciferase (ERSE-FLuc) was employed (Yoshida et al. 1998; Nadanaka et al. 2006, 2007). The dependence of ERSE-FLuc activation on XBP1s and ATF6 in HEK293DAX cells that stably express tet-inducible XBP1s and a trimethoprim-regulated dihydrofolate reductase (DHFR)-ATF6 revealed that $\mathrm{BiP}$ is preferentially induced by ATF6 (Lee et al. 2003; Shoulders et al. 2013). The ERSE-FLuc reporter was stably transfected into a HEK293T-Rex cell clone that was employed to screen the 644,951 small-molecule Scripps Drug Discovery Library to identify molecules that activate the ERSE-FLuc reporter with robust statistics (Plate et al. 2016a). A subset of these molecules was previously shown to activate the cytosolic heat shock response utilizing an analogous transcriptional reporter assay and were therefore eliminated from further consideration (Calamini et al. 2012). The top 281 compounds remaining were counterscreened using a luciferase reporter assay reporting on the activation of the IRE1/XBP1s arm of the UPR. Two-thirds of the screening hits activate the ERSE-FLuc 
J.W. Kelly

reporter $>2$-fold better than the XBP1s-RLuc reporter, indicating ATF6 arm-selective UPR activation and demonstrating the power of the screening strategy. Multiplex gene expression (MGE) profiling was then performed on all 281 hits individually in HEK293T-Rex cells to identify compounds that preferentially activate the ATF6 transcriptional program relative to other possibilities. The Wiseman Laboratory recently developed a targeted RNA-seq approach that scrutinizes the selectivity of stress-responsive pathway activation utilizing multiple reporter genes from each transcriptional program. As the RNA-seq methodology decreases in price, it will soon be practical to carry out an RNA-seq experiment to evaluate the extent that an ATF6-activating compound recapitulates the transcriptional reprogramming selectivity afforded by the transcription factor itself.

The small molecule $N$-(2-hydroxy-5-methylphenyl)-3-phenylpropanamide 147 (Fig. 3) up-regulates the majority of transcripts up-regulated by the ATF6 transcription factor itself, based on an RNA-seq experiment, although the amplitude of changes in transcript levels is about $50 \%$ that afforded by the ATF6 transcription factor (Plate et al. 2016a). Of all the molecules we analyzed in detail thus far, compound 147 appears to be the most selective ATF6 activator. The 2-amino- $p$-cresol substructure comprises the majority of the top 79 ATF6 activators exhibiting good selectivity for activation of the ATF6 transcriptional program over the other UPR transcriptional programs, as well as other stress-responsive signaling pathways. The activation of the ATF6 arm of the UPR by 147 requires that ATF6 is present. No 147 ATF6 acti-

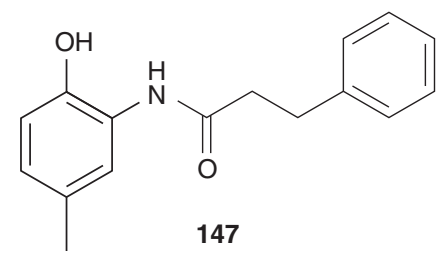

Figure 3. Line drawing depiction of the chemical structure of the small-molecule ATF6 selective activator 147. vation is observed in $\mathrm{ATF}^{-1-}$ mouse embryonic fibroblasts (Plate et al. 2016a). Compound 147 also requires site-1 protease activity for ATF6 activation, as pharmacological inhibition of site-1 protease antagonizes the function of 147 (Plate et al. 2016a).

\section{MEDICINAL CHEMICAL AND CHEMICAL BIOLOGICAL EFFORTS SUGGEST THAT 147 REACTS WITH ER DISULFIDE ISOMERASES ACTIVATING THE ATF6 ARM OF THE UPR}

The ATF6 arm of the UPR appears to be activated in response to ER stress through a process involving reduction of inter- and intramolecular disulfides in ATF6 that results in formation of a reduced ATF6 monomer that is trafficking competent (Nadanaka et al. 2006, 2007). The hypothesis is that this reduced ATF6 monomer traffics to the Golgi where it is processed by the site- 1 and site- 2 proteases to generate the $N$-terminal fragment of ATF6, the active transcription factor responsible for the transcriptional program (Ye et al. 2000a,b).

The acetylated 2-amino- $p$-cresol substructure in 147 and related ATF6 selective activators originating from the high-throughput screen suggested to us that 147-dependent ATF6 activation may involve metabolic oxidation of 147 by $\mathrm{P} 450$ s to form a quinone methide that preferentially reacts with a protein(s) leading to ATF6 activation (Paxman et al. 2018). This idea is consistent with the result that 147 becomes inactive when cotreated with the P450 inhibitor resveratrol (Paxman et al. 2018). Analogs of 147 wherein the methyl or the hydroxy group are substituted are inactive, also indicating that functional groups required for forming the quinone methide are critical for ATF6 activation (Paxman et al. 2018). Fortunately, we were able to prepare a version of $\mathbf{1 4 7}$ bearing an alkyne (i.e., 147-alkyne) (Fig. 4), that activates the ATF6 arm of the UPR analogously to $\mathbf{1 4 7}$. The quinone methide was envisioned to form an irreversible covalent conjugate with cellular proteins, including the target(s) responsible for activation of the ATF6 arm of the UPR (Fig. 4). A copper-catalyzed azide-alkyne cycloaddition 


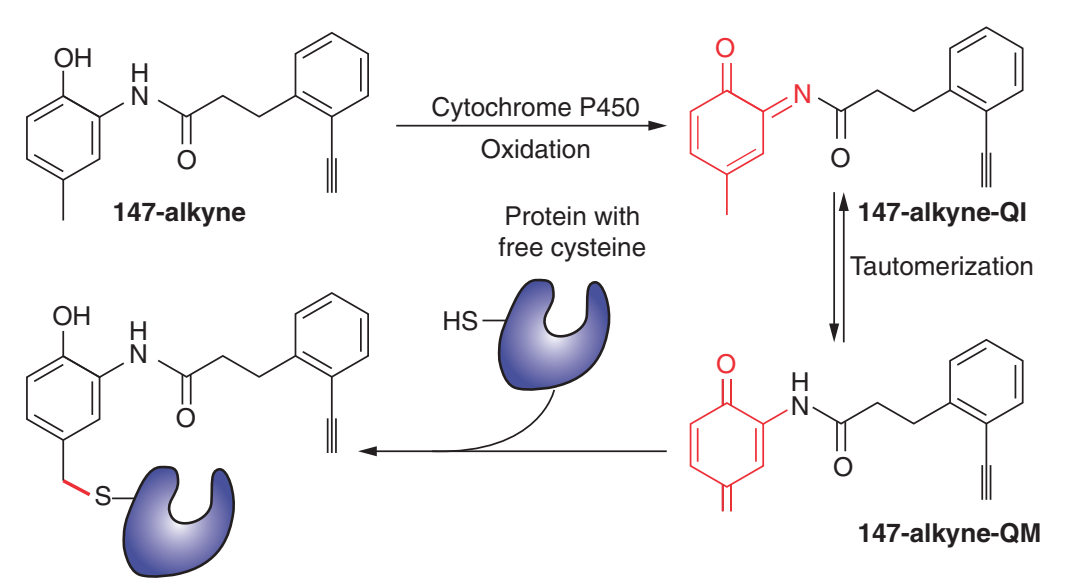

Figure 4. Line drawing depiction of the chemical structure of the small-molecule ATF6 selective activator 147alkyne employed for target identification using affinity chromatography mass spectrometry-mass spectrometry. 147-alkyne undergoes oxidation to form a QM or a QI, which gets labeled covalently by protein conjugates. (Figure adapted from Paxman et al. 2018 and reprinted under the terms of the Creative Commons Attribution License.)

or (CuAAC) "click" reaction (BesanceneyWebler et al. 2011) between an azide-functionalized biotin (Yang et al. 2010) and the alkyne now covalently attached to its target enables affinity chromatography-mass spectrometrymass spectrometry bottom-up mass spectrometry to identify the target or targets of 147-alkyne (Paxman et al. 2018).

We showed that $\mathbf{1 4 7}$ activates the ATF6 arm of the UPR in an ALMC-2 plasma cell line derived from a light chain amyloidosis patient. We prepared lysates from ALMC-2 cells treated with 147-alkyne for $18 \mathrm{~h}$, and the biotin affinity tag was clicked on to facilitate affinity chromatography using streptavidin beads. The 147-alkynebased protein conjugates isolated by this approach were subjected to SDS-PAGE. In-gel digestion of the 147-alkyne conjugates followed by mass spectrometry-mass spectrometry characterization identified four ER protein disulfide isomerases (PDIA1, PDIA4, PDIA6, and TXNDC5), as prevalent bands on the SDSPAGE that were efficiently eliminated by adding a 5-fold excess of 147 together with 147-alkyne during the 18-h treatment period (Paxman et al. 2018). An affinity chromatography mass spectrometry-mass spectrometry experiment employing 147-alkyne, with and without compet- itor 147 (no affinity tag), employing tandem mass tags for multiplexing identified another two protein disulfide isomerases (PDIA3 and TMX1) in addition to the four disulfide isomerases (PDIA1, PDIA4, PDIA6, and TXNDC5), already identified by SDS-PAGE, that form conjugates with 147 (Paxman et al. 2018). Disulfide isomerases caught our attention because it is logical to see how impeding their activity through 147 conjugation could lead to net reduction of ATF6, permitting its trafficking and enabling ATF6 activation (Nadanaka et al. 2006, 2007). The observed modification of ER-localized proteins by $\mathbf{1 4 7}$ that results in activation of the ATF6 arm of the UPR is not a general feature of other small-molecule quinone methides, which modify most thiol-containing proteins in multiple compartments of the cell (Backus et al. 2016). Collectively, these data support the notion that $\mathbf{1 4 7}$ is a prodrug that gets activated by $\mathrm{P} 450$ in or proximal to the ER, activating the ATF6 arm of the UPR by leading to net reduction of ATF6 (Paxman et al. 2018). A relevant example of a more typical quinone methide is celastrol, which is triterpenoid natural product that harbors a quinone methide that activates numerous stress-responsive signaling pathways (targets in numerous compartments), including 
J.W. Kelly

the antioxidant response and the heat shock response (Westerheide et al. 2004; Trott et al. 2008).

To further scrutinize the proposed mechanism of action of 147, a genetic approach was applied, wherein PDIA1, PDIA3, PDIA4, PDIA5, or PDIA6 were short hairpin RNA (shRNA)-depleted by $25 \%-50 \%$ based on PCR assessment. These results demonstrate that modest depletion of a subset of PDIs selectively inhibits 147-dependent activation of ATF6, suggesting that covalent modification of PDIA3, PDIA4, and PDIA5 contribute to ATF6 activation by 147 (Paxman et al. 2018).

Additional studies on the mechanism of action of 147 examined a set of small molecules called Ceapins discovered by the Walter group (Gallagher and Walter 2016; Gallagher et al. 2016). Ceapins inhibit ER ATF6 activation by stress through stabilizing ATF6 oligomers in the ER and preventing ATF6 monomer trafficking to the Golgi. Stabilization of ATF6 oligomers by Ceapins should inhibit 147-dependent ATF6 activation by preventing disulfide-mediated disruption of the ATF6 oligomers into the reduced monomers required for trafficking. Indeed, 147dependent activation of ATF6 was inhibited by coadministration of increasing concentrations of the Ceapin, CP7 (Paxman et al. 2018). These data are consistent with 147 playing an important role in promoting ATF6 disulfide reduction through protein disulfide isomerase conjugation and ATF6 dissociation prior to ATF6 trafficking to the Golgi for proteolytic activation. Thus, the small molecule 147 appears to be a prodrug converted into a quinone methide electrophile in or in proximity to the ER, which preferentially activates the ATF6 signaling pathway without activating other stress-responsive signaling pathways (Paxman et al. 2018). Other stress-responsive signaling pathways can be activated by similar electrophiles, including the IRE1 and PERK UPR signaling pathways, the heat shock response, and the NRF2 oxidative stress response. Thus, it is remarkable that transcriptional profiling by RNA-seq and other approaches demonstrates how selective ATF6 activation by 147 is (Plate et al. 2016a; Paxman et al. 2018).

\section{TOWARD AMELIORATION OF DISEASES THROUGH ATF6 ACTIVATION}

The capacity of the UPR stress-responsive signaling pathways to distinctly influence ER proteostasis by transcriptional reprogramming and translational attenuation has significant potential to alleviate proteinopathies associated with secreted proteins (Hetz 2012). Here I will focus on the potential of activating the ATF6 arm of the UPR for ameliorating diverse proteinopathies.

In collaboration with Chris Glembotski, an expert in myocardial ischemia/reperfusion injury, the Glembotski, Wiseman, and Kelly Laboratories demonstrated that selective pharmacologic activation of the ATF6 arm of the UPR by IV administration of $147(2 \mathrm{mg} / \mathrm{Kg})$ during reperfusion preserves heart function in a murine model of myocardial ischemia/reperfusion injury (Blackwood et al. 2019). The ATF6 target genes were up-regulated in the heart after IV injection of 147, with transcript levels reaching a maximum level at $24 \mathrm{~h}$ and falling to baseline over the course of a week. To examine the influence of ATF6 activation by 147 in various murine tissues, an inactive control compound that closely resembles 147 or 147 were administered by IV, and the effects of these compounds on tissue damage were examined in the heart via the acute ischemia/reperfusion murine model, in the murine kidney via transient unilateral renal portal system occlusion, and in the brain via transient unilateral middle cerebral artery occlusion (Blackwood et al. 2019). Notably, even when administered only at the time of reperfusion, 147 significantly decreased infarct sizes in all three tissues when measured $24 \mathrm{~h}$ after reperfusion (Blackwood et al. 2019). Thus, pharmacologic activation of the ATF6 stressresponsive signaling pathway is a proteostasis network-reprogramming-based therapeutic strategy for ameliorating ischemia/reperfusion damage, highlighting the potential of arm-selective UPR activation for treating a wide range of diseases (Hetz 2012; Plate et al. 2016b; Blackwood et al. 2019).

The systemic amyloid diseases result from the secretion of destabilized, properly folded amyloidogenic proteins into the blood that un- 
dergo conformational excursions during circulation in the extracellular space, facilitating aggregation into a spectrum of proteotoxic aggregates including amyloid fibrils (Eisele et al. 2015). The pharmacologic and genetic evidence that protein aggregation causes the destruction of postmitotic tissue leading to neurodegenerative diseases and degenerative diseases in general is compelling (Coelho et al. 2012, 2013; Maurer et al. 2018). We showed that chemical genetic up-regulation of the ATF6 transcription factor increases ER quality control stringency for the amyloidogenic protein transthyretin, preferentially reducing secretion of disease-associated transthyretin variants proportional to the variants' tetramer destabilization (Shoulders et al. 2013; Chen et al. 2014). Decreased variant transthyretin secretion slows extracellular, concentration-dependent aggregation of transthyretin. Thus, the selective small-molecule activator of ATF6 147 was expected to reduce the secretion of destabilized mutated transthyretin from hepatocytes, wherein 147 activates the ATF6 arm of the UPR. Hepatocytes pretreated with 147 reduced A25T transthyretin secretion by $45 \%$, without altering wild-type transthyretin secretion or the secretion of the endogenous secreted proteome, according to ${ }^{35} \mathrm{~S}$ metabolic labeling (Plate et al. 2016a). Thus, it seems clear the ATF6 activation has the potential to ameliorate human amyloid diseases by enhancing ER quality control (i.e., degradation of mutant secreted amyloidogenic proteins).

\section{CONCLUSION}

Considerable effort goes into validating a pharmacologic agent, such as the ATF6 activator 147 outlined above. However, once 147 pharmacodynamics are validated, the small molecule can be used in a spectrum of disease models to discern utility. Having a validated ATF6 activator with established murine tissue pharmacodynamics, even allows negative data in murine models of disease to be interpreted with some confidence. Pharmacologic activators of additional stress-responsive signaling pathways either have been or are in the process of being validated. Having this collection of stress- responsive signaling pathway activators will be very useful for establishing clinical uses for a diverse collection of stress-responsive signaling pathway modulators.

\section{REFERENCES}

Arias E, Cuervo AM. 2011. Chaperone-mediated autophagy in protein quality control. Curr Opin Cell Biol 23: 184189. doi:10.1016/j.ceb.2010.10.009

Backus KM, Correia BE, Lum KM, Forli S, Horning BD, González-Páez GE, Chatterjee S, Lanning BR, Teijaro JR, Olson AJ, et al. 2016. Proteome-wide covalent ligand discovery in native biological systems. Nature 534: 570574. doi:10.1038/nature18002

Balch WE, Morimoto RI, Dillin A, Kelly JW. 2008. Adapting proteostasis for disease intervention. Science 319: 916919. doi:10.1126/science.1141448

Ben-Zvi A, Miller EA, Morimoto RI. 2009. Collapse of proteostasis represents an early molecular event in Caenorhabditis elegans aging. Proc Natl Acad Sci 106: 14914 14919. doi:10.1073/pnas.0902882106

Besanceney-Webler C, Jiang H, Zheng TQ, Feng L, Soriano del Amo D, Wang W, Klivansky LM, Marlow FL, Liu Y, Wu P. 2011. Increasing the efficacy of bioorthogonal click reactions for bioconjugation: A comparative study. Angew Chem Int Ed Engl 50: 8051-8056. doi:10.1002/anie .201101817

Blackwood EA, Azizi K, Thuerauf DJ, Paxman RJ, Plate L, Kelly JW, Wiseman RL, Glembotski CC. 2019. Pharmacologic ATF6 activation confers global protection in widespread disease models by reprograming cellular proteostasis. Nat Commun 10: 187. doi:10.1038/s41467-01808129-2

Boyce M, Bryant KF, Jousse C, Long K, Harding HP, Scheuner D, Kaufman RJ, Ma D, Coen DM, Ron D, et al. 2005 A selective inhibitor of eIF2 $\alpha$ dephosphorylation protects cells from ER stress. Science 307: 935-939. doi:10.1126/ science.1101902

Brodsky JL. 2012. Cleaning up: ER-associated degradation to the rescue. Cell 151: 1163-1167. doi:10.1016/j.cell.2012 .11 .012

Brodsky JL, McCracken AA. 1997. ER-associated and proteasome-mediated protein degradation: How two topologically restricted events came together. Trends Cell Biol 7: 151-156. doi:10.1016/S0962-8924(97)01020-9

Bulawa CE, Connelly S, DeVit M, Wang L, Weigel C, Fleming JA, Packman J, Powers ET, Wiseman RL, Foss TR, et al. 2012. Tafamidis, a potent and selective transthyretin kinetic stabilizer that inhibits the amyloid cascade. Proc Natl Acad Sci 109: 9629-9634. doi:10.1073/pnas .1121005109

Calamini B, Silva MC, Madoux F, Hutt DM, Khanna S, Chalfant MA, Saldanha SA, Hodder P, Tait BD, Garza D, et al. 2012. Small-molecule proteostasis regulators for protein conformational diseases. Nat Chem Biol 8: 185196. doi:10.1038/nchembio.763

Chartron JW, Hunt KCL, Frydman J. 2016. Cotranslational signal-independent SRP preloading during membrane targeting. Nature 536: 224-228. doi:10.1038/nature19309 
J.W. Kelly

Chen X, Yin XM. 2011. Coordination of autophagy and the proteasome in resolving endoplasmic reticulum stress. Vet Pathol 48: 245-253. doi:10.1177/0300985810385154

Chen JJ, Genereux JC, Qu S, Hulleman JD, Shoulders MD, Wiseman RL. 2014. ATF6 activation reduces the secretion and extracellular aggregation of destabilized variants of an amyloidogenic protein. Chem Biol 21: 1564-1574. doi:10 .1016/j.chembiol.2014.09.009

Choi SW, Reixach N, Connelly S, Johnson SM, Wilson IA, Kelly JW. 2010. A substructure combination strategy to create potent and selective transthyretin kinetic stabilizers that prevent amyloidogenesis and cytotoxicity. J Am Chem Soc 132: 1359-1370. doi:10.1021/ja908562q

Coelho T, Maia LF, Martins da Silva AM, Waddington Cruz MW, Plante-Bordeneuve V, Lozeron P, Suhr OB, Campistol JM, Conceicao IM, Schmidt HHJ, et al. 2012. Tafamidis for transthyretin familial amyloid polyneuropathy: A randomized, controlled trial. Neurology 79: 785-792. doi:10.1212/WNL.0b013e3182661eb1

Coelho T, Maia LF, da Silva AM, Cruz MW, Planté-Bordeneuve V, Suhr OB, Conceiçao I, Schmidt HHJ, Trigo P, Kelly JW, et al. 2013. Long-term effects of tafamidis for the treatment of transthyretin familial amyloid polyneuropathy. J Neurol 260: 2802-2814. doi:10.1007/s00415013-7051-7

Cohen FE, Kelly JW. 2003. Therapeutic approaches to protein-misfolding diseases. Nature 426: 905-909. doi:10 $.1038 /$ nature02265

Cohen E, Bieschke J, Perciavalle RM, Kelly JW, Dillin A. 2006. Opposing activities protect against age-onset proteotoxicity. Science 313: 1604-1610. doi:10.1126/science .1124646

Cohen E, Paulsson JF, Blinder P, Burstyn-Cohen T, Du D, Estepa G, Adame A, Pham HM, Holzenberger M, Kelly JW, et al. 2009. Reduced IGF-1 signaling delays age-associated proteotoxicity in mice. Cell 139: 1157-1169. doi:10 .1016/j.cell.2009.11.014

Cohen E, Du D, Joyce D, Kapernick EA, Volovik Y, Kelly JW, Dillin A. 2010. Temporal requirements of insulin/IGF-1 signaling for proteotoxicity protection. Aging Cell 9: 126134. doi:10.1111/j.1474-9726.2009.00541.x

Cooley CB, Ryno LM, Plate L, Morgan GJ, Hulleman JD, Kelly JW, Wiseman RL. 2014. Unfolded protein response activation reduces secretion and extracellular aggregation of amyloidogenic immunoglobulin light chain. Proc Natl Acad Sci 111: 13046-13051. doi:10.1073/pnas .1406050111

Cowen LE, Singh SD, Köhler JR, Collins C, Zaas AK, Schell WA, Aziz H, Mylonakis E, Perfect JR, Whitesell L, et al. 2009. Harnessing Hsp90 function as a powerful, broadly effective therapeutic strategy for fungal infectious disease. Proc Natl Acad Sci 106: 2818-2823. doi:10.1073/pnas .0813394106

Cuervo AM, Dice JF. 1996. A receptor for the selective uptake and degradation of proteins by lysosomes. Science 273: 501-503. doi:10.1126/science.273.5274.501

Culyba EK, Price JL, Hanson SR, Dhar A, Wong CH, Gruebele M, Powers ET, Kelly JW. 2011. Protein native-state stabilization by placing aromatic side chains in $\mathrm{N}$-glycosylated reverse turns. Science 331: 571-575. doi:10.1126/ science. 1198461
Dai C, Whitesell L, Rogers AB, Lindquist S. 2007. Heatshock factor 1 is a powerful multifaceted modifier of carcinogenesis. Cell 130: 1005-1018. doi:10.1016/j.cell.2007 .07 .020

Didomenico BJ, Bugaisky GE, Lindquist S. 1982. The heatshock is self-regulated at both the transcriptional and posttranslational levels. Cell 31: 593-603. doi:10.1016/ 0092-8674(82)90315-4

Eisele YS, Monteiro C, Fearns C, Encalada SE, Wiseman RL, Powers ET, Kelly JW. 2015. Targeting protein aggregation for the treatment of degenerative diseases. Nat Rev Drug Discov 14: 759-780. doi:10.1038/nrd4593

Ellgaard L, Molinari M, Helenius A. 1999. Setting the standards: Quality control in the secretory pathway. Science 286: 1882-1888. doi:10.1126/science.286.5446.1882

Ellis RJ, Hartl FU. 1999. Principles of protein folding in the cellular environment. Curr Opin Struct Biol 9: 102-110. doi:10.1016/S0959-440X(99)80013-X

Eriksson S, Carlson J, Velez R. 1986. Risk of cirrhosis and primary liver-cancer in $\alpha_{1}$-antitrypsin deficiency. $N E n g l J$ Med 314: 736-739. doi:10.1056/NEJM198603203141202

Fan JQ. 2001. Potential drug therapies for lysosomal storage disorders. Front Biotechnol Pharm 2: 275-291.

Fan JQ. 2003. A contradictory treatment for lysosomal storage disorders: Inhibitors enhance mutant enzyme activity. Trends Pharmacol Sci 24: 355-360. doi:10.1016/ S0165-6147(03)00158-5

Fan JQ, Ishii S, Asano N, Suzuki Y. 1999. Accelerated transport and maturation of lysosomal $\alpha$-galactosidase $\mathrm{A}$ in Fabry lymphoblasts by an enzyme inhibitor. Nature Med 5: 112-115. doi:10.1038/4801

Fewell SW, Travers KJ, Weissman JS, Brodsky JL. 2001. The action of molecular chaperones in the early secretory pathway. Annu Rev Genet 35: 149-191. doi:10.1146/an nurev.genet.35.102401.090313

Finley D. 2009. Recognition and processing of ubiquitinprotein conjugates by the proteasome. Annu Rev Biochem 78: 477-513. doi:10.1146/annurev.biochem.78.081507 .101607

Gallagher CM, Walter P. 2016. Ceapins inhibit ATF6 $\alpha$ signaling by selectively preventing transport of ATF $6 \alpha$ to the Golgi apparatus during ER stress. eLife 5: e11880. doi:10 $.7554 /$ LLife. 11880

Gallagher CM, Garri C, Cain EL, Ang KKH, Wilson CG, Chen S, Hearn BR, Jaishankar P, Aranda-Diaz A, Arkin MR, et al. 2016. Ceapins are a new class of unfolded protein response inhibitors, selectively targeting the ATF6 $\alpha$ branch. eLife 5: e11878. doi:10.7554/eLife.11878

Ghosh R, Lipson KL, Sargent KE, Mercurio AM, Hunt JS, Ron D, Urano F. 2010. Transcriptional regulation of VEGF-A by the unfolded protein response pathway. PLoS ONE 5: e9575. doi:10.1371/journal.pone.0009575

Gidalevitz T, Ben-Zvi A, Ho KH, Brignull HR, Morimoto RI. 2006. Progressive disruption of cellular protein folding in models of polyglutamine diseases. Science 311: 14711474. doi:10.1126/science.1124514

Hammarstrom P, Wiseman RL, Powers ET, Kelly JW. 2003. Prevention of transthyretin amyloid disease by changing protein misfolding energetics. Science 299: 713-716. doi:10.1126/science.1079589 
Hartl FU, Bracher A, Hayer-Hartl M. 2011. Molecular chaperones in protein folding and proteostasis. Nature 475: 324-332. doi:10.1038/nature10317

Hebert DN, Lamriben L, Powers ET, Kelly JW. 2014. The intrinsic and extrinsic effects of $\mathrm{N}$-linked glycans on glycoproteostasis. Nat Chem Biol 10: 902-910. doi:10.1038/ nchembio. 1651

Hetz C. 2012. The unfolded protein response: Controlling cell fate decisions under ER stress and beyond. Nat Rev Mol Cell Biol 13: 89-102. doi:10.1038/nrm3270

Jarosz DF, Taipale M, Lindquist S. 2010. Protein homeostasis and the phenotypic manifestation of genetic diversity: Principles and mechanisms. Annu Rev Genet 44: 189216. doi:10.1146/annurev.genet.40.110405.090412

Johnson AE. 2009. The structural and functional coupling of two molecular machines, the ribosome and the translocon. J Cell Biol 185: 765-767. doi:10.1083/jcb.200902014

Johnson SM, Wiseman RL, Sekijima Y, Green NS, AdamskiWerner SL, Kelly JW. 2005. Native state kinetic stabilization as a strategy to ameliorate protein misfolding diseases: A focus on the transthyretin amyloidoses. Acc Chem Res 38: 911-921. doi:10.1021/ar020073i

Johnson SM, Wiseman RL, Reixach N, Paulsson JF, Choi S, Powers ET, Buxbaum JN, Kelly JW. 2010. Understanding and ameliorating the TTR amyloidoses, pp. 967-1003. Wiley, New York.

Kon M, Cuervo AM. 2010. Autophagy: An alternative degradation mechanism for misfolded proteins, pp. 113-129. Wiley, New York.

Kruse KB, Brodsky JL, McCracken AA. 2006. Autophagy: An ER protein quality control process. Autophagy 2: 135137. doi:10.4161/auto.2.2.2388

Kudo T, Kanemoto S, Hara H, Morimoto N, Morihara T, Kimura R, Tabira T, Imaizumi K, Takeda M. 2008. A molecular chaperone inducer protects neurons from ER stress. Cell Death Differ 15: 364-375. doi:10.1038/sj.cdd .4402276

Labbadia J, Morimoto RI. 2015. Repression of the heat shock response is a programmed event at the onset of reproduction. Mol Cell 59: 639-650. doi:10.1016/j.molcel.2015.06 .027

Lamark T, Johansen T. 2010. Autophagy: Links with the proteasome. Curr Opin Cell Biol 22: 192-198. doi:10 $.1016 /$ j.ceb.2009.11.002

Larkin A, Imperiali B. 2011. The expanding horizons of asparagine-linked glycosylation. Biochemistry 50: 44114426. doi:10.1021/bi200346n

Lecker SH, Goldberg AL, Mitch WE. 2006. Protein degradation by the ubiquitin-proteasome pathway in normal and disease states. J Am Soc Nephrol 17: 1807-1819. doi:10 $.1681 /$ ASN.2006010083

Lee AH, Iwakoshi NN, Glimcher LH. 2003. XBP-1 regulates a subset of endoplasmic reticulum resident chaperone genes in the unfolded protein response. Mol Cell Biol 23: 7448-7459. doi:10.1128/MCB.23.21.7448-7459.2003

Lee BH, Lee MJ, Park S, Oh DC, Elsasser S, Chen PC, Gartner C, Dimova N, Hanna J, Gygi SP, et al. 2010. Enhancement of proteasome activity by a small-molecule inhibitor of USP14. Nature 467: 179-184. doi:10.1038/nature09299

Leggett DS, Hanna J, Borodovsky A, Crosas B, Schmidt M, Baker RT, Walz T, Ploegh H, Finley D. 2002. Multiple
Adapting Proteostasis in the Secretory Pathway

associated proteins regulate proteasome structure and function. Mol Cell 10: 495-507. doi:10.1016/S1097-2765 (02)00638-X

Li H, Korennykh AV, Behrman SL, Walter P. 2010. Mammalian endoplasmic reticulum stress sensor IRE1 signals by dynamic clustering. Proc Natl Acad Sci 107: 1611316118. doi:10.1073/pnas.1010580107

Maier T, Ferbitz L, Deuerling E, Ban N. 2005. A cradle for new proteins: Trigger factor at the ribosome. Curr Opin Struct Biol 15: 204-212. doi:10.1016/j.sbi.2005.03.005

Makley LN, McMenimen KA, DeVree BT, Goldman JW, McGlasson BN, Rajagopal P, Dunyak BM, McQuade TJ, Thompson AD, Sunahara R, et al. 2015. Pharmacological chaperone for $\alpha$-crystallin partially restores transparency in cataract models. Science 350: 674-677. doi:10.1126/ science.aac9145

Marciniak SJ, Ron D. 2006. Endoplasmic reticulum stress signaling in disease. Physiological Rev 86: 1133-1149. doi:10.1152/physrev.00015.2006

Maurer MS, Schwartz JH, Gundapaneni B, Elliott PM, Merlini G, Waddington-Cruz M, Kristen AV, Grogan M, Witteles R, Damy T, et al. 2018. Tafamidis treatment for patients with transthyretin amyloid cardiomyopathy. N Engl J Med 379: 1007-1016. doi:10.1056/NEJ Moa1805689

McCracken AA, Brodsky JL. 2003. Evolving questions and paradigm shifts in endoplasmic-reticulum-associated degradation (ERAD). BioEssays 25: 868-877. doi:10 $.1002 /$ bies. 10320

McCracken AA, Werner ED, Brodsky JL. 1998. Endoplasmic reticulum-associated protein degradation: An unconventional route to a familiar fate. Adv Mol Cell Biol 27: 165200. doi:10.1016/S1569-2558(08)60461-0

Merz F, Boehringer D, Schaffitzel C, Preissler S, Hoffmann A, Maier T, Rutkowska A, Lozza J, Ban N, Bukau B, et al. 2008. Molecular mechanism and structure of trigger factor bound to the translating ribosome. EMBO J 27: 16221632. doi:10.1038/emboj.2008.89

Miroy GJ, Lai Z, Lashuel HA, Peterson SA, Strang C, Kelly JW. 1996. Inhibiting transthyretin amyloid fibril formation via protein stabilization. Proc Natl Acad Sci 93: 15051-15056. doi:10.1073/pnas.93.26.15051

Mori K. 2000. Tripartite management of unfolded proteins in the endoplasmic reticulum. Cell 101: 451-454. doi:10 .1016/S0092-8674(00)80855-7

Morimoto RI. 1998. Regulation of the heat shock transcriptional response: Cross talk between a family of heat shock factors, molecular chaperones, and negative regulators. Genes Dev 12: 3788-3796. doi:10.1101/gad.12.24.3788

Morimoto RI, Cuervo AM. 2009. Protein homeostasis and aging: Taking care of proteins from the cradle to the grave. J Gerontol A Biol Sci Med Sci 64: 167-170. doi:10.1093/ gerona/gln 071

Morley JF, Brignull HR, Weyers JJ, Morimoto RI. 2002. The threshold for polyglutamine-expansion protein aggregation and cellular toxicity is dynamic and influenced by aging in Caenorhabditis elegans. Proc Natl Acad Sci 99: 10417-10422. doi:10.1073/pnas.152161099

Mu TW, Fowler DM, Kelly JW. 2008a. Partial restoration of mutant enzyme homeostasis in three distinct lysosomal storage disease cell lines by altering calcium homeostasis. PLoS Biol 6: e26. doi:10.1371/journal.pbio.0060026 
J.W. Kelly

Mu TW, Ong DST, Wang YJ, Balch WE, Yates JR III, Segatori L, Kelly JW. 2008b. Chemical and biological approaches synergize to ameliorate protein-folding diseases. Cell 134: 769-781. doi:10.1016/j.cell.2008.06.037

Nadanaka S, Yoshida H, Mori K. 2006. Reduction of disulfide bridges in the lumenal domain of ATF6 in response to glucose starvation. Cell Struct Funct 31: 127-134. doi:10 $.1247 / \mathrm{csf} .06024$

Nadanaka S, Okada T, Yoshida H, Mori K. 2007. Role of disulfide bridges formed in the luminal domain of ATF6 in sensing endoplasmic reticulum stress. Mol Cell Biol 27: 1027-1043. doi:10.1128/MCB.00408-06

Nakatsukasa K, Brodsky JL. 2008. The recognition and retrotranslocation of misfolded proteins from the endoplasmic reticulum. Traffic 9: 861-870. doi:10.1111/j.16000854.2008.00729.x

Paxman R, Plate L, Blackwood EA, Glembotski C, Powers ET, Wiseman RL, Kelly JW. 2018. Pharmacologic ATF6 activating compounds are metabolically activated to selectively modify endoplasmic reticulum proteins. eLife 7: e37168. doi:10.7554/eLife.37168

Plate L, Cooley CB, Chen JJ, Paxman RJ, Gallagher CM, Madoux F, Genereux JC, Dobbs W, Garza D, Spicer TP, et al. 2016a. Small molecule proteostasis regulators that reprogram the ER to reduce extracellular protein aggregation. eLife 5: e15550. doi:10.7554/eLife.15550

Plate L, Paxman RJ, Wiseman RL, Kelly JW. 2016b. Unfolded protein response modulating protein quality control. eLife 5: e18431. doi:10.7554/eLife.18431

Powers ET, Morimoto RI, Dillin A, Kelly JW, Balch WE. 2009. Biological and chemical approaches to diseases of proteostasis deficiency. Annu Rev Biochem 78: 959-991. doi:10.1146/annurev.biochem.052308.114844

Preissler S, Deuerling E. 2012. Ribosome-associated chaperones as key players in proteostasis. Trends Biochem Sci 37: 274-283. doi:10.1016/j.tibs.2012.03.002

Razavi H, Palaninathan SK, Powers ET, Wiseman RL, Purkey HE, Mohamedmohaideen NN, Deechongkit S, Chiang KP, Dendle MTA, Sacchettini JC, et al. 2003. Benzoxazoles as transthyretin amyloid fibril inhibitors: Synthesis, evaluation, and mechanism of action. Angew Chem Int Ed Engl 42: 2758-2761. doi:10.1002/anie.200351179

Ron D, Walter P. 2007. Signal integration in the endoplasmic reticulum unfolded protein response. Nature Rev Mol Cell Biol 8: 519-529. doi:10.1038/nrm2199

Sawkar AR, Cheng WC, Beutler E, Wong CH, Balch WE, Kelly JW. 2002. Chemical chaperones increase the cellular activity of N370S $\beta$-glucosidase: A therapeutic strategy for Gaucher disease. Proc Natl Acad Sci 99: 15428-15433. doi:10.1073/pnas.192582899

Sawkar AR, D'Haeze W, Kelly JW. 2006. Therapeutic strategies to ameliorate lysosomal storage disorders-A focus on Gaucher disease. Cell Mol Life Sci 63: 1179-1192. doi:10.1007/s00018-005-5437-0

Schröder M, Kaufman RJ. 2005. The mammalian unfolded protein response. Ann Rev Biochem 74: 739-789. doi:10 .1146/annurev.biochem.73.011303.074134

Sekijima Y, Dendle MA, Kelly JW. 2006. Orally administered diflunisal stabilizes transthyretin against dissociation required for amyloidogenesis. Amyloid 13: 236-249. doi:10 $.1080 / 13506120600960882$
Shan So S, Walter P. 2005. Co-translational protein targeting by the signal recognition particle. FEBS Lett 579: 921926. doi:10.1016/j.febslet.2004.11.049

Shang J, Gao N, Kaufman RJ, Ron D, Harding HP, Lehrman MA. 2007. Translation attenuation by PERK balances ER glycoprotein synthesis with lipid-linked oligosaccharide flux. J Cell Biol 176: 605-616. doi:10.1083/jcb.200607007

Shoulders MD, Ryno LM, Genereux JC, Moresco JJ, Tu PG, Wu CL, Yates JR, Su AI, Kelly JW, Wiseman RL. 2013. Stress-independent activation of XBP1s and/or ATF6 reveals three functionally diverse ER proteostasis environments. Cell Rep 3: 1279-1292. doi:10.1016/j.celrep.2013 .03 .024

Solis GM, Kardakaris R, Valentine ER, Bar-Peled L, Chen AL, Blewett MM, McCormick MA, Williamson JR, Kennedy B, Cravatt BF, et al. 2018. Translation attenuation by minocycline enhances longevity and proteostasis in old post-stress-responsive organisms. eLife 7: e40314. doi:10 .7554/eLife.40314

Taipale M, Jarosz DF, Lindquist S. 2010. HSP90 at the hub of protein homeostasis: Emerging mechanistic insights. Nat Rev Mol Cell Biol 11: 515-528. doi:10.1038/nrm2918

Tang YC, Chang HC, Hayer-Hartl M, Hartl FU. 2007. SnapShot: Molecular chaperones, part II. Cell 128: 412. doi:10 $.1016 /$ j.cell.2007.01.013

Tojo K, Sekijima Y, Kelly JW, Si I. 2006. Diflunisal stabilizes familial amyloid polyneuropathy-associated transthyretin variant tetramers in serum against dissociation required for amyloidogenesis. Neurosci Res 56: 441-449. doi:10.1016/j.neures.2006.08.014

Trott A, West JD, Klaić L, Westerheide SD, Silverman RB, Morimoto RI, Morano KA. 2008. Activation of heat shock and antioxidant responses by the natural product celastrol: Transcriptional signatures of a thiol-targeted molecule. Mol Biol Cell 19: 1104-1112. doi:10.1091/mbc.e0710-1004

Tsaytler P, Harding HP, Ron D, Bertolotti A. 2011. Selective inhibition of a regulatory subunit of protein phosphatase 1 restores proteostasis. Science 332: 91-94. doi:10.1126/ science. 1201396

Tsvetkov AS, Miller J, Arrasate M, Wong JS, Pleiss MA, Finkbeiner S. 2010. A small-molecule scaffold induces autophagy in primary neurons and protects against toxicity in a Huntington disease model. Proc Natl Acad Sci 107: 16982-16987. doi:10.1073/pnas.1004498107

Vidal M, Cusick ME, Barabási AL. 2011. Interactome networks and human disease. Cell 144: 986-998. doi:10 $.1016 /$ j.cell.2011.02.016

Voisine C, Pedersen JS, Morimoto RI. 2010. Chaperone networks: Tipping the balance in protein folding diseases. Neurobiol Dis 40: 12-20. doi:10.1016/j.nbd.2010.05.007

Walter P, Ron D. 2011. The unfolded protein response: From stress pathway to homeostatic regulation. Science 334: 1081-1086. doi:10.1126/science.1209038

Werner ED, Brodsky JL, McCracken AA. 1996. Proteasomedependent endoplasmic reticulum-associated protein degradation: An unconventional route to a familiar fate. Proc Natl Acad Sci 93: 13797-13801. doi:10.1073/pnas.93 .24 .13797

Westerheide SD, Morimoto RI. 2005. Heat shock response modulators as therapeutic tools for diseases of protein 
conformation. J Biol Chem 280: 33097-33100. doi:10 $.1074 /$ jbc.R500010200

Westerheide SD, Bosman JD, Mbadugha BNA, Kawahara TLA, Matsumoto G, Kim S, Gu W, Devlin JP, Silverman RB, Morimoto RI. 2004. Celastrols as inducers of the heat shock response and cytoprotection. J Biol Chem 279: 56053-56060. doi:10.1074/jbc.M409267200

Westerheide SD, Anckar J, Stevens SM Jr, Sistonen L, Morimoto RI. 2009. Stress-inducible regulation of heat shock factor 1 by the deacetylase SIRT1. Science 323: 10631066. doi:10.1126/science. 1165946

Whitesell L, Lindquist S. 2009. Inhibiting the transcription factor HSF1 as an anticancer strategy. Expert Opin Ther Targets 13: 469-478. doi:10.1517/14728220902832697

Williams DB. 2006. Beyond lectins: The calnexin/calreticulin chaperone system of the endoplasmic reticulum. J Cell Sci 119: 615-623. doi:10.1242/jcs.02856

Wiseman RL, Haynes CM, Ron D. 2010. SnapShot: The unfolded protein response. Cell 140: 590-590.e2. doi:10 .1016/j.cell.2010.02.006

Wong E, Cuervo AM. 2010. Autophagy gone awry in neurodegenerative diseases. Nat Neurosci 13: 805-811. doi:10 $.1038 / \mathrm{nn} .2575$

Yam AY, Xia Y, Lin HTJ, Burlingame A, Gerstein M, Frydman J. 2008. Defining the TRiC/CCT interactome links chaperonin function to stabilization of newly made proteins with complex topologies. Nat Struct Mol Biol 15: 1255-1262. doi:10.1038/nsmb.1515

Yang YY, Grammel M, Raghavan AS, Charron G, Hang HC. 2010. Comparative analysis of cleavable azobenzenebased affinity tags for bioorthogonal chemical proteomics. Chem Biol 17: 1212-1222. doi:10.1016/j.chembiol .2010 .09 .012
Adapting Proteostasis in the Secretory Pathway

Ye J, Rawson RB, Dave UP, Prywes R, Goldstein JL, Brown MS. 2000a. Site-1 protease (S1P) and site-2 protease (S2P), the two proteases that cleave membrane-bound SREBPs, also cleave ATF6 upon ER stress. Mol Biol Cell 11: 290A.

Ye J, Rawson RB, Komuro R, Chen X, Davé UP, Prywes R, Brown MS, Goldstein JL. 2000b. ER stress induces cleavage of membrane-bound ATF6 by the same proteases that process SREBPs. Mol Cell 6: 1355-1364. doi:10.1016/ S1097-2765(00)00133-7

Yoshida Y. 2003. Quality control of proteins in secretory pathway by N-glycans. Kagaku Kogyo 54: 771-776.

Yoshida H, Haze K, Yanagi H, Yura T, Mori K. 1998. Identification of the cis-acting endoplasmic reticulum stress response element responsible for transcriptional induction of mammalian glucose-regulated proteins-Involvement of basic leucine zipper transcription factors. J Biol Chem 273: 33741-33749. doi:10.1074/jbc.273.50.33741

Yost HJ, Petersen RB, Linquist S. 1990. RNA metabolism: Strategies for regulation in the heat shock response. Trends Genet 6: 223-227. doi:10.1016/0168-9525(90) 90183-7

Young JC, Agashe VR, Siegers K, Hartl FU. 2004. Pathways of chaperone-mediated protein folding in the cytosol. Nat Rev Mol Cell Biol 5: 781-791. doi:10.1038/nrm1492

Yu ZQ, Sawkar AR, Whalen LJ, Wong CH, Kelly JW. 2007. Isofagomine- and 2,5-anhydro-2,5-imino-D-glucitol-based glucocerebrosidase pharmacological chaperones for Gaucher disease intervention. J Med Chem 50: 94-100. doi:10.1021/jm060677i

Zhu K, Dunner K, McConkey DJ. 2010. Proteasome inhibitors activate autophagy as a cytoprotective response in human prostate cancer cells. Oncogene 29: 451-462. doi:10.1038/onc.2009.343 


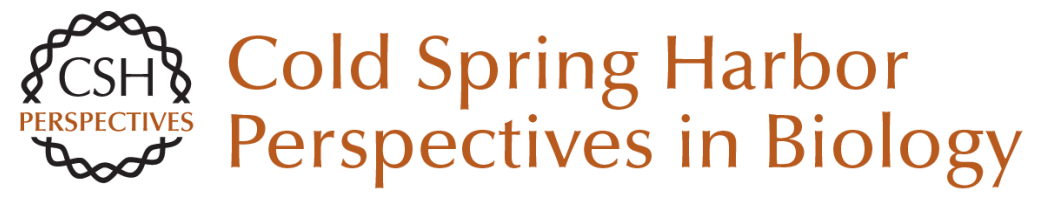

\section{Pharmacologic Approaches for Adapting Proteostasis in the Secretory Pathway to Ameliorate Protein Conformational Diseases}

Jeffery W. Kelly

Cold Spring Harb Perspect Biol 2020; doi: 10.1101/cshperspect.a034108 originally published online May 14, 2019

\section{Subject Collection Protein Homeostasis}

Proteome-Scale Mapping of Perturbed

Proteostasis in Living Cells

Isabel Lam, Erinc Hallacli and Vikram Khurana

Pharmacologic Approaches for Adapting

Proteostasis in the Secretory Pathway to

Ameliorate Protein Conformational Diseases Jeffery W. Kelly

Cell-Nonautonomous Regulation of Proteostasis

in Aging and Disease

Richard I. Morimoto

The Autophagy Lysosomal Pathway and

Neurodegeneration Steven Finkbeiner

Functional Modules of the Proteostasis Network Gopal G. Jayaraj, Mark S. Hipp and F. Ulrich Hartl

Protein Solubility Predictions Using the CamSol

Method in the Study of Protein Homeostasis Pietro Sormanni and Michele Vendruscolo

Recognition and Degradation of Mislocalized Proteins in Health and Disease

Ramanujan S. Hegde and Eszter Zavodszky

The Nuclear and DNA-Associated Molecular Chaperone Network

Zlata Gvozdenov, Janhavi Kolhe and Brian C. Freeman
The Amyloid Phenomenon and Its Significance in

Biology and Medicine

Christopher M. Dobson, Tuomas P.J. Knowles and Michele Vendruscolo

A Chemical Biology Approach to the Chaperome

in Cancer-HSP90 and Beyond

Tony Taldone, Tai Wang, Anna Rodina, et al.

Proteostasis in Viral Infection: Unfolding the

Complex Virus-Chaperone Interplay

Ranen Aviner and Judith Frydman

The Proteasome and Its Network: Engineering for

Adaptability

Daniel Finley and Miguel A. Prado

Functional Amyloids

Daniel Otzen and Roland Riek

Chaperone Interactions at the Ribosome Elke Deuerling, Martin Gamerdinger and Stefan G. Kreft

Mechanisms of Small Heat Shock Proteins Maria K. Janowska, Hannah E.R. Baughman, Christopher N. Woods, et al.

Structure, Function, and Regulation of the Hsp90 Machinery

Maximilian M. Biebl and Johannes Buchner

For additional articles in this collection, see http://cshperspectives.cshlp.org/cgi/collection/

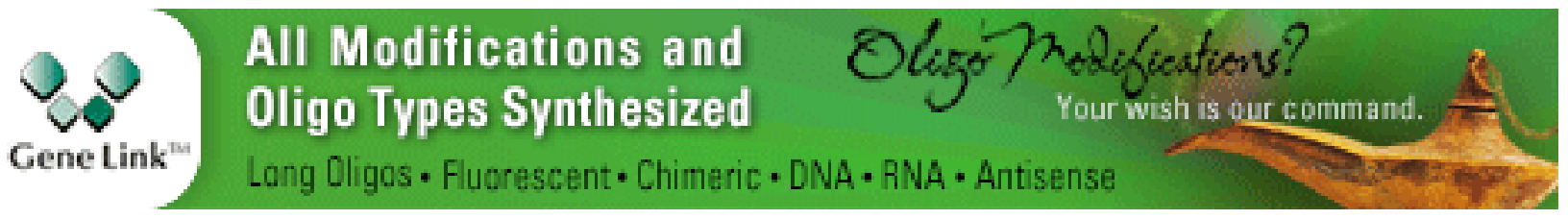


For additional articles in this collection, see http://cshperspectives.cshlp.org/cgi/collection/

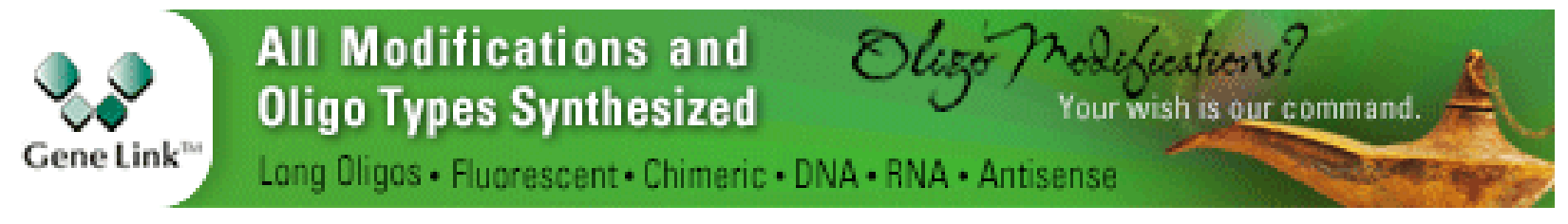

Copyright @ 2020 Cold Spring Harbor Laboratory Press; all rights reserved 